ARTICLE

https://doi.org/10.1038/s41467-019-08900-z

\title{
Enantioselective Rhodium-Catalyzed Cycloisomerization of 1,6-Allenynes to access 5/6-Fused Bicycle[4.3.0]nonadienes
}

\author{
Xu Deng (1) 1,2,3, Li-Yang Shi ${ }^{3}$, Jialing Lan ${ }^{1,4}$, Yu-Qing Guan³ ${ }^{3}$ Xiaoyong Zhang (1) ${ }^{1}$, Hui Lv (D) ${ }^{3}$, \\ Lung Wa Chung (i) $^{1} \&$ Xumu Zhang ${ }^{1}$
}

Transition-metal-catalyzed cycloisomerization of 1,n-allenynes represents a powerful synthetic tool to rapidly assemble complex polycyclic skeletons from simple linear substrates. Nevertheless, there are no reports of the asymmetric version of these reactions. Moreover, most of these reactions proceed through a 6-endo-dig cyclization pathway, which preferentially delivers the distal product (via 5/5 rhodacyclic intermediate) rather than the proximal one (via 6/5 rhodacyclic intermediate). Herein, we report an enantioselective rhodium(I)-catalyzed cycloisomerization of 1,6-allenynes to provide the proximal product 5/6-fused bicycle[4.3.0]nonadienes in good yields and with excellent enantioselectivities. Remarkably, this chemistry works perfectly for 1,6-allenynes having a cyclic substituent within the allene component, thereby affording synthetically formidable tricyclic products with excellent enantioselectivities. Moreover, extensive DFT calculations suggest an uncommon pathway involving 5-exo-dig cycloisomerization, ring-expansion, rate-determining alkene isomerization involving $\mathrm{C}_{\mathrm{sp} 3}-\mathrm{H}$ activation, $\mathrm{C}-\mathrm{C}$ activation of the cyclobutene moiety and finally reductive elimination. Deuterium labeling experiments support the ratedetermining step involving the $\mathrm{C}-\mathrm{H}$ bond activation in this transformation.

\footnotetext{
${ }^{1}$ Shenzhen Grubbs Institute and Department of Chemistry, Southern University of Science and Technology, Shenzhen 518055, China. ${ }^{2}$ College of Xiangya Pharmaceutical Sciences, Central South University, Changsha 410013, China. ${ }^{3}$ Key Laboratory of Biomedical Polymers of Ministry of Education \& College of Chemistry and Molecular Sciences, Engineering Research Center of Organosilicon Compounds \& Materials, Ministry of Education, Wuhan University, Wuhan, Hubei 430072, China. ${ }^{4}$ School of Chemistry and Chemical Engineering, Harbin Institute of Technology, Harbin 150001, China. These authors contribute equally: Xu Deng, Li-Yang Shi, Jialing Lan. Correspondence and requests for materials should be addressed to H.L. (email: huilv@whu.edu.cn) or to L.W.C. (email: oscarchung@sustc.edu.cn) or to X.Z. (email: zhangxm@sustc.edu.cn)
} 
A pre-eminent goal of synthetic chemistry is the highlyselective construction of targeted structural complexity in an atom- and step-economy fashion ${ }^{1}$. Transition metalcatalyzed cycloisomerization reactions of $1, \mathrm{n}$-allenynes provide a powerful synthetic approach in this regard, as they facilitate the rapid assembly of complex polycyclic skeletons from simple linear substrates ${ }^{2}$. Since Malacria's seminal work on the cobalt-catalyzed cycloisomerization of $1, n$-allenynes ${ }^{3}$, a variety of metals, such as $\mathrm{Rh}, \mathrm{Au}, \mathrm{Pt}, \mathrm{Ru}, \mathrm{Pd}, \mathrm{Co}, \mathrm{Ti}, \mathrm{Ag}, \mathrm{Ga}$ and $\mathrm{Mo}$, have been reported to catalyze the reaction, which proceeds through the common metallacyclic or carbocation intermediate. Among these contributions, rhodium is of particular interest with respect to the metallacycle pathway. To this end, Brummond reported the first rhodium(I)-catalyzed cycloisomerization of 1,6-allenynes during the screening of the effect of transition metals on the allenic Pauson-Khand reaction ${ }^{4}$, which afforded the commonly observed Alder-ene type product, namely a cross-conjugated triene through the formation of a rhodabicyclic intermediate followed by $\beta$-hydride elimination ${ }^{5-10}$. Recently, a diverse set of rhodium (I)-catalyzed cyclizations of 1,6-allenynes involving either siteselective $\mathrm{C}-\mathrm{H}$ or $\mathrm{C}-\mathrm{C}$ activation processes have been reported. For example, Sato described a rhodium(I)-catalyzed cyclopropanation/cyclization sequence of tert-butylallene-alkynes, which involves $\mathrm{C}_{\mathrm{sp} 3}-\mathrm{H}$ activation directed by the formation of metallacycles, thus giving cyclopropanes in moderate to good yields ${ }^{11}$. Mukai reported a similar rhodium(I)-catalyzed cycloisomerization of 1,6-allenynes $\mathbf{A}$ through $\mathrm{C}_{\mathrm{sp} 3}-\mathrm{H}^{12}$ and $\mathrm{C}_{\mathrm{sp} 2}-\mathrm{H}^{13-15}$ activation to furnish polycyclic products $\mathbf{D}$ efficiently (Fig. 1a). In addition, Mukai also reported a series of rhodium(I)-catalyzed cycloisomerization reactions of allenylcycloalkane-alkynes $\mathbf{E}(n=$ $1-3)$ through a metallacycle directed $\beta$-carbon elimination to access a variety of bicyclic products $\mathbf{H}$ (Fig. $1 b)^{12,16-20}$. These reactions can be tentatively rationalized by the initial formation of the rhodabicyclo $[4,3,0]$ intermediate $\mathbf{B} / \mathbf{F}$, followed by the activation of the $\mathrm{C}-\mathrm{H}$ and/or $\mathrm{C}-\mathrm{C}$ bond proximal to the rhodium(I) center, which presumably collapses to the final products through reductive elimination ${ }^{12,20-23}$. Interestingly, $\mathrm{C}-\mathrm{H}$ activation and $\mathrm{C}-\mathrm{C}$ activation compete in some cases, which can be finely tuned by the careful selection of the rhodium(I) catalyst ${ }^{12,14}$. Although a diverse set of cycloisomerization reactions of $1, n$-allenynes have been disclosed, to the best of our knowledge, there are no reports on the related asymmetric reactions. Additionally, all the examples involving rhodium(I)-catalyzed $\mathrm{C}-\mathrm{H}$ and/or $\mathrm{C}-\mathrm{C}$ activation of allenynes require no $\alpha-\mathrm{H}$ at the allenic terminal of the substrate to prevent $\beta$-hydride elimination of the possible rhodacyclic intermediate $\mathbf{B} / \mathbf{F}^{13,15-20,24,25}$.

As part of our continuing interests in asymmetric transitionmetal-catalyzed cyclizations ${ }^{26-31}$, we now disclose an enantioselective rhodium(I)-catalyzed cycloisomerization of 1,6-allenynes through an unusual 5-exo-dig cyclization followed by an alkene isomerization via a $\mathrm{C}_{\mathrm{sp} 3}-\mathrm{H}$ activation process, which enables the synthesis of 5/6-fused bicycle[4.3.0]nonadienes in good yields and excellent enantioselectivities by careful selection of the chiral bisphosphine ligand (Fig. 1c). This work also represents a rare example of a reaction with substrates with $\alpha-\mathrm{H}$ at the allenic terminal that favor $\mathrm{C}_{\mathrm{sp} 3}-\mathrm{H}$ activation rather than $\beta$-hydride elimination.

\section{Results}

Reaction optimization. Previous reports revealed that the intramolecular cycloisomerization of $\mathrm{N}$-tethered 1,6-allenynes catalyzed by a rhodium(I) complex modified with a bidentate ligand provided the exclusive formation of the commonly observed Alder-ene product ${ }^{4-7,9-11,32-34}$. Since multiple factors, including the ancillary ligands, the counter-ions and the solvent can dramatically impact the course of rhodium(I)-catalyzed reactions ${ }^{35}$, there are significant opportunities to expand the synthetic possibilities for these highly reactive $\pi$ components, namely, 1,6-allenynes, towards the rhodium(I) catalyst by careful selection of reaction conditions ${ }^{2}$. We envisaged that rhodium(I)

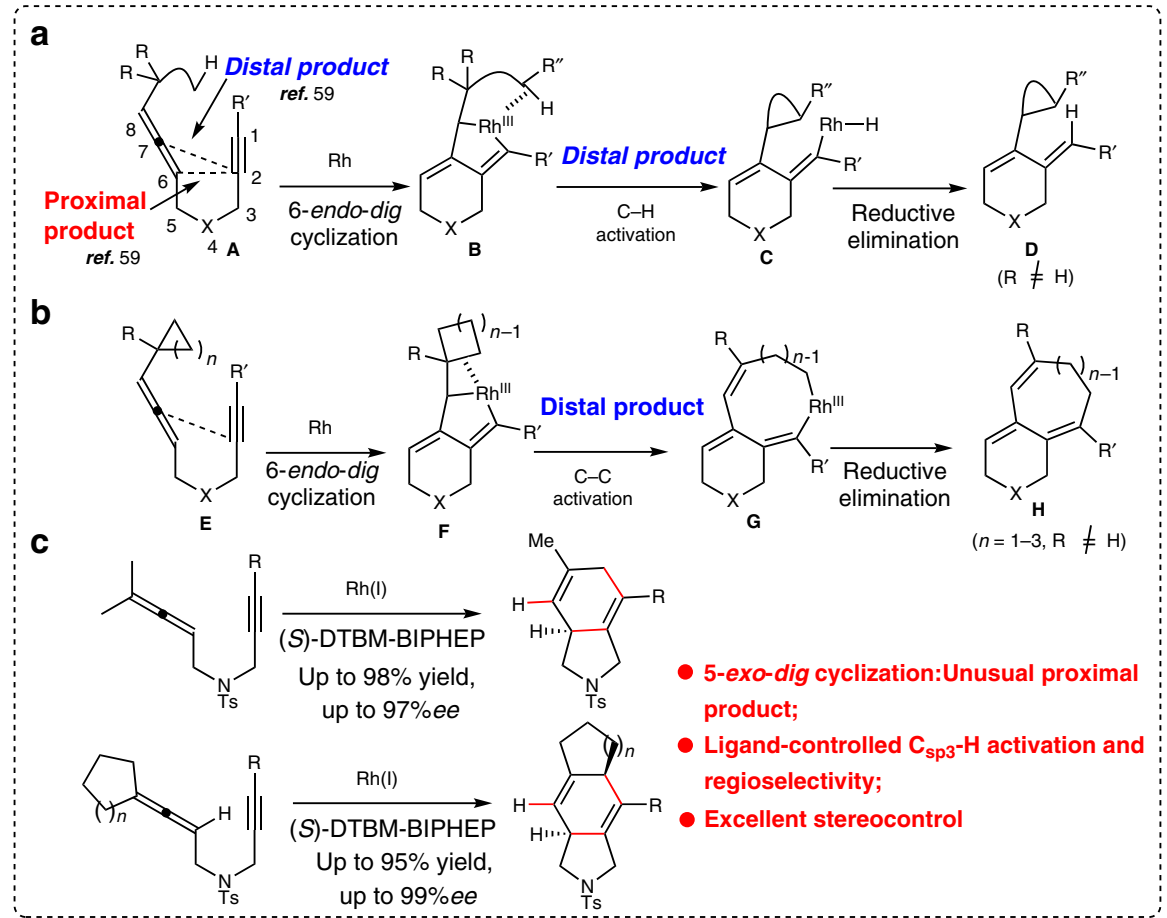

Fig. 1 Transition metal-catalyzed cycloisomerization of 1,6-allenynes. a Transition metal-catalyzed cycloisomerization of 1,6-allenynes involving C-H activation. $\mathbf{b}$ Transition metal-catalyzed cycloisomerization of 1,6-allenynes involving C-C activation. $\mathbf{c}$ This work: enantioselective rhodium(I)-catalyzed cycloisomerization of 1,6-allenynes to form proximal product 5/6-fused bicycle[4.3.0]nonadienes 
species with a single vacant coordination site for the substrate would exhibit significantly different reactivity and selectivity ${ }^{36-38}$. Therefore, we further investigated the influence of the rhodium(I) catalyst and solvent effects on the reaction. Treatment of 1a with the chiral rhodium(I) complex generated in situ from [Rh $\left.\left(\mathrm{CH}_{2} \mathrm{CH}_{2}\right)_{2} \mathrm{Cl}\right]_{2}(5 \mathrm{~mol} \%)$ and various chiral diphosphines (10 $\mathrm{mol} \%)$ and $\mathrm{PPh}_{3}(10 \mathrm{~mol} \%)$ in the presence of silver salt $(20 \mathrm{~mol}$ $\%)$ in degassed 1,2-dicholoroethane at room temperature indicates that the product distribution is highly ligand-dependent (Table 1 entries 1-4). For instance, L1-L3 furnished the commonly observed Alder-ene type product 3a exclusively (entries 1, 2,3 ), whereas the highly strained and electron-rich C2-symmetric biarylphosphane ligand L4 furnished the unexpected 5/6-fused cycloadduct $\mathbf{2 a}$, along with $\mathbf{3} \mathbf{a}$ in moderate yield, albeit with poor enantio-induction (entry 4). This result motivated further investigations to improve regio- and enantioselectivity of the reaction. Interestingly, replacing the pre-catalyst $\left[\mathrm{Rh}\left(\mathrm{CH}_{2} \mathrm{CH}_{2}\right)_{2} \mathrm{Cl}\right]_{2}$ to a cationic (entry 5) and neutral rhodium(I) precursor (entry 6) were inefficient, either leading to no conversion or the exclusive formation of 3a. Gratifyingly, the examination of the solvent on product formation and distribution led to significant improvements. For instance, 1,4-dioxane gave encouraging regio- and enantio-induction (entries 10 and 11), whereas other solvents, such as $\mathrm{CHCl}_{3}$, toluene, THF, were inferior (entries 7-9). Similar solvent effects were also observed by Sato and coworkers in their investigation of the ruthenium(I)-catalyzed cyclization of 1,6allenynes $^{39}$. Moreover, closer examination of the influence of silver salts revealed that counter-ions exerted negligible effects on the reaction outcomes. Subsequent screening of monodentate ligands demonstrated that $\mathrm{PCy}_{3}$ delivered the desired $\mathbf{2 a}$ in good yield, along with satisfactory regioselectivity and excellent enantioselectivity (entry 12). Additionally, the reaction proceeds smoothly in the absence of an additional monodentate ligand, albeit with modest regio-selection. This suggests that additional ligand is not necessary for the reaction, whereas it improves the regio- and enantiocontrol. Finally, control experiments demonstrated that $\mathrm{AgBF}_{4}$ did not catalyze the cyclization in the absence of rhodium, thereby indicating a rhodium-specific reaction.

Substrate scope. In light of the promising preliminary results with the optimal catalyst system (Table 1, entry 12), we selected to examine the scope and limitations of this rhodium(I)-catalyzed cycloisomerization of 1,6-allenynes (Table 2). For $N$-tethered substrates, the reactions are sensitive to the substituent on the

Table 1 Reaction development and optimizations

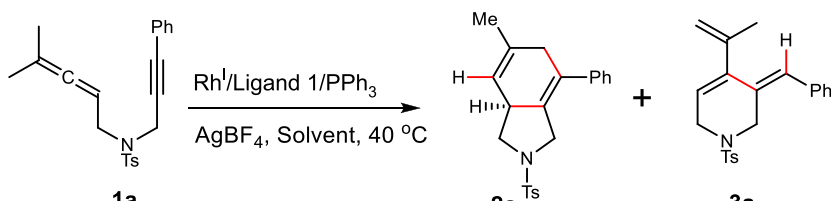

\begin{tabular}{|c|c|c|c|c|c|c|}
\hline Entry $^{\mathbf{a}}$ & {$[\mathbf{M X}]$} & Ligand 1 & Solvent & Yield $^{b}$ & $2 a: 3 a^{c}$ & ee $(\%)^{d}$ \\
\hline 1 & {$\left[\left\{\mathrm{Rh}\left(\mathrm{CH}_{2} \mathrm{CH}_{2}\right)_{2} \mathrm{Cl}\right\}_{2}\right]$} & L1 & DCE & 88 & $0: 100$ & - \\
\hline 2 & {$\left[\left\{\mathrm{Rh}\left(\mathrm{CH}_{2} \mathrm{CH}_{2}\right)_{2} \mathrm{Cl}\right\}_{2}\right]$} & L2 & DCE & 36 & $0: 100$ & - \\
\hline 3 & {$\left[\left\{\mathrm{Rh}\left(\mathrm{CH}_{2} \mathrm{CH}_{2}\right)_{2} \mathrm{Cl}\right\}_{2}\right]$} & $\mathbf{L 3}$ & DCE & 94 & $0: 100$ & - \\
\hline 4 & {$\left[\left\{\mathrm{Rh}\left(\mathrm{CH}_{2} \mathrm{CH}_{2}\right)_{2} \mathrm{Cl}\right\}_{2}\right]$} & L4 & DCE & 76 & $32: 68$ & 39 \\
\hline 5 & {$\left[\left\{\mathrm{Rh}(\mathrm{NBD})_{2} \mathrm{BF}_{4}\right\}\right]$} & L4 & DCE & $\mathrm{NR}^{[\mathrm{f}]}$ & - & - \\
\hline 6 & {$\left[\{\mathrm{Rh}(\mathrm{NBD}) \mathrm{Cl}\}_{2}\right]$} & L4 & DCE & 22 & $0: 100$ & - \\
\hline 7 & {$\left[\left\{\mathrm{Rh}\left(\mathrm{CH}_{2} \mathrm{CH}_{2}\right)_{2} \mathrm{Cl}\right\}_{2}\right]$} & L4 & Toluene & 20 & $9: 91$ & 27 \\
\hline 8 & {$\left[\left\{\mathrm{Rh}\left(\mathrm{CH}_{2} \mathrm{CH}_{2}\right)_{2} \mathrm{Cl}\right\}_{2}\right]$} & L4 & THF & 10 & $10: 90$ & 24 \\
\hline 9 & {$\left[\left\{\mathrm{Rh}\left(\mathrm{CH}_{2} \mathrm{CH}_{2}\right)_{2} \mathrm{Cl}\right\}_{2}\right]$} & L4 & $\mathrm{CHCl}_{3}$ & 14 & $30: 70$ & 0 \\
\hline 10 & {$\left[\left\{\mathrm{Rh}\left(\mathrm{CH}_{2} \mathrm{CH}_{2}\right)_{2} \mathrm{Cl}\right\}_{2}\right]$} & L4 & Dioxane $^{\mathrm{e}}$ & 67 & $38: 62$ & 81 \\
\hline 11 & {$\left[\left\{\mathrm{Rh}\left(\mathrm{CH}_{2} \mathrm{CH}_{2}\right)_{2} \mathrm{Cl}\right\}_{2}\right]$} & L5 & Dioxane $^{\mathrm{e}}$ & 61 & $45: 55$ & 75 \\
\hline $12^{g}$ & {$\left[\left\{\mathrm{Rh}\left(\mathrm{CH}_{2} \mathrm{CH}_{2}\right)_{2} \mathrm{Cl}\right\}_{2}\right]$} & L4 & Dioxane $^{e}$ & 82 & $85: 15$ & 90 \\
\hline
\end{tabular}

Dioxane $e^{\mathrm{e}}$

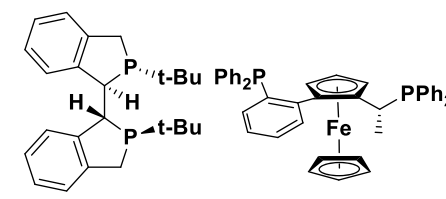

$(S p, R c)$ - DuanPhos (L1) WalPhos(L2)

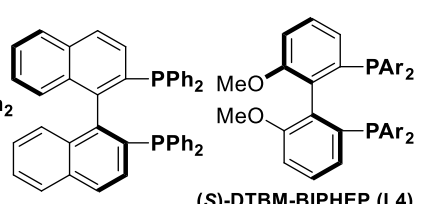

(S)-BINAP(L3) $\mathrm{Ar}=3,5-\mathrm{di}^{-}{ }^{\mathrm{B}} \mathrm{Bu}-4-\mathrm{MeO}-\mathrm{C}_{6} \mathrm{H}_{2} \mathrm{Ar}=3,5-\mathrm{di}-{ }^{t} \mathrm{Bu}-4-\mathrm{MeO}-\mathrm{C}_{6} \mathrm{H}_{2}$

NBD, norbornadiene; DCE, 1,2-dicholoroethane; THF, tetrahydrofuran

aAll the reactions were conducted with $\mathbf{1 a}(0.1 \mathrm{mmol})$ with an in situ generated ligand (10 mol\%)-PPh $(10 \mathrm{~mol} \%)-\mathrm{Rh}(\mathrm{I})(5 \mathrm{~mol} \%)$ complex in the presence of $\mathrm{Ag}(\mathrm{I})$ salt (20 mol\%) in degassed solvent at $40^{\circ} \mathrm{C}$ unless otherwise noted

bThe combined yield of $\mathbf{2} \mathbf{a}$ and $\mathbf{3 a}$, isolated yields were reported

cDetermined by ${ }^{1} \mathrm{H}-\mathrm{NMR}$ of the mixture

dDetermined by HPLC using a chiral stationary phase, See Supplementary Figure 4

e1,4-Dioxane

${ }_{\mathrm{PPC}} \mathrm{y}_{3}$ was used as the additional ligand

hWithout use of the additional ligand

The bold values means the results under the optimal conditions 


\section{Table 2 Cycloisomerization of 1,6-allenynes}

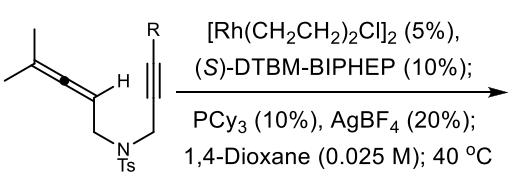

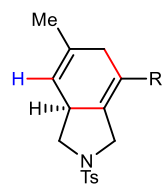

2

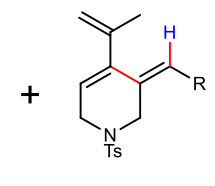

3

\begin{tabular}{ccccc}
\hline Entry $^{\mathbf{a}}$ & Substitutents & Yield (\%) & Ratio & ee $(\mathbf{\%})^{\mathbf{d}}$ \\
\hline 1 & $\mathrm{R}=2-\mathrm{F}-\mathrm{C}_{6} \mathrm{H}_{4}$ & 93 & $\mathbf{2 b : 3 b}=73: 27$ & 89 \\
2 & $\mathrm{R}=3-\mathrm{Me}-\mathrm{C}_{6} \mathrm{H}_{4}$ & 82 & $\mathbf{2 c : 3 c}=84: 16$ & 80 \\
3 & $\mathrm{R}=3-\mathrm{F}-\mathrm{C}_{6} \mathrm{H}_{4}$ & 86 & $\mathbf{2 d : 3 d}=88: 12$ & 97 \\
4 & $\mathrm{R}=3-\mathrm{CN}-\mathrm{C}_{6} \mathrm{H}_{4}$ & 65 & $\mathbf{2 e : 3 e}=95: 5$ & 45 \\
5 & $\mathrm{R}=4-\mathrm{Me}-\mathrm{C}_{6} \mathrm{H}_{4}$ & 89 & $\mathbf{2 f :} \mathbf{3 f}=13: 87$ & 88 \\
6 & $\mathrm{R}=4-\mathrm{MeO}-\mathrm{C}_{6} \mathrm{H}_{4}$ & 81 & $\mathbf{2 g}: \mathbf{3 g}=80: 20$ & 78 \\
7 & $\mathrm{R}=4-\mathrm{Cl}-\mathrm{C}_{6} \mathrm{H}_{4}$ & 85 & $\mathbf{2 h}: \mathbf{3 h}=50: 50$ & 90 \\
8 & $\mathrm{R}=4-\mathrm{Br}-\mathrm{C}_{6} \mathrm{H}_{4}$ & 98 & $\mathbf{2 i}: \mathbf{3 i}=60: 40$ & 94 \\
9 & $\mathrm{R}=2-$ naphthyl & 52 & $\mathbf{2 j}: \mathbf{3 j}=45: 55$ & 55 \\
10 & $\mathrm{R}=2-$ thiophenyl & 65 & $\mathbf{2 k}: \mathbf{3 k}=40: 60$ & 92
\end{tabular}

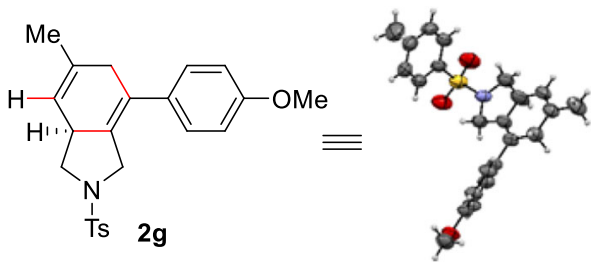

a The reactions were conducted with $\mathbf{1}(0.1 \mathrm{mmol})$ with in situ generated complex with $(\mathrm{S})-\mathrm{DTBM}-\mathrm{BIPHEP}(10 \mathrm{~mol} \%), \mathrm{PCy} \mathrm{H}_{3}(10 \mathrm{~mol} \%),\left[\left\{\mathrm{Rh}\left(\mathrm{CH}_{2} \mathrm{CH}_{2}\right)_{2} \mathrm{Cl}\right\}_{2}\right](5 \mathrm{~mol} \%)$ in the presence of $\mathrm{AgBF}{ }_{4}(20 \mathrm{~mol}$ $\%)$ in 1,4-dioxane at $40^{\circ} \mathrm{C}$ unless otherwise noted; ${ }^{b}$ The combined yield of $\mathbf{2}$ and $\mathbf{3}$, isolated yields were reported; ${ }^{\mathrm{c}}$ Determined by ${ }^{1} \mathrm{H}$-NMR of the mixture; ${ }^{d}$ Determined by HPLC using a chiral stationary phase, see Supplementary Figures $41-51$

alkyne terminus. All ortho-, meta- and para-substituted aryl groups are generally well tolerated (entries 1-8), affording the desired 5/6-fused cycloadducts in moderate to good yields with good to excellent enantioselectivities. Additionally, the aryl substitution pattern has an interesting impact on the reaction outcome. For example, electron-withdrawing groups proved to be beneficial to the yields, regio- and enantioselectivities (entries 1, 3, 4,7 and 8), whereas electron-donating groups are detrimental (entries 2, 5 and 6). In addition, the 3-cyano aryl substituent led to low level of enantioinduction (entry 4), which may be attributed to the chelation to the rhodium center. Hetero-aryl groups on the alkyne terminus are also well tolerated (entry 10); however, $\mathrm{N}$-tethered 1,6-allenynes with terminal alkynes $(\mathrm{R}=\mathrm{H}$, Supplementary Table 1, entry 3), or containing alkyl groups or other functional groups on the alkyne terminus (Supplementary Table 1, entries 1, 2 and 4), including $O$-tethered congeners (Supplementary Table 1, entries 5 and 6) afforded the exclusive formation of the Alder-ene type product, without any detectable amount of the corresponding 5/6-fused bicyclic product. These results indicate that the reaction is sensitive to the subtle changes in the nature of the tether and substituent. X-ray crystallographic analysis of $\mathbf{2 g}$ unambiguously established its structure possessing a bicycle[4.3.0]nonadiene framework with the absolute configuration of C8 having an $S$ configuration.

Encouraged by aforementioned results, we wondered if the current catalytic system was also applicable to substrates with cyclic subunits within the allene component. Thus, several cyclic 1,6-allenynes were examined (Table 3). Gratifyingly, 1,6-allenynes both having a five-membered or a six-membered cyclic substituent within the allene proceed smoothly and provide improved results, thereby delivering the synthetically challenging tricyclic adducts 5 in high yields with excellent regio- and stereoselectivities (entries 1-4). In particular, the reactions displayed excellent diastereoselectivities (entries 1-4). For each example examined, only one diastereoisomer was detected by HPLC in addition to ${ }^{1} \mathrm{H}-\mathrm{NMR}(400 \mathrm{MHz})$. The proposed relative stereochemical assignment of $\mathbf{5 c}$ was assigned based on the NOESY analysis (See Supplementary Figure 16).

Mechanistic studies. To gain some insight into the reaction mechanism, we investigated the cyclization of $\left[D_{6}\right]-1$ a under the optimal reaction conditions (Table 1 , entry 12). As expected, the reaction gave a mixture of the desired 5/6-fused bicyclic product $\left[\mathrm{D}_{6}\right]-\mathbf{2 a}$ and Alder-ene type product $\left[\mathrm{D}_{6}\right]-\mathbf{3 a}$ with the ratio of $1: 1$, wherein deuterium atom was transferred to the expected position in high content (Fig. 2a). In addition, a kinetic isotope competition experiment using an equimolar mixture of $\mathbf{1 a}$ and $\left[\mathrm{D}_{6}\right]-\mathbf{1 a}$ by quenching at early stages $(1-3 \mathrm{~h})$ revealed that the reaction gave a mixture of $2 \mathbf{a}$ and $\left[D_{6}\right]-2 \mathbf{a}$ in $12 \sim 20 \%$ yield with the ratio of $68: 32 \sim 73: 27$. The corresponding KIE was estimated to be $\sim 2.5$ (Fig. 2b). These results suggested that the rate-determining step probably involves $\mathrm{C}-\mathrm{H}$ bond activation or formation.

To further understand the reaction mechanism of this unusual rhodium(I)-catalyzed cycloisomerization of 1,6-allenynes, an 


\section{Table 3 Cycloisomerization of cyclic 1,6-allenynes}<smiles>[R]C#CCNCC=CC1CCCC1</smiles>

4
$\left[\mathrm{Rh}\left(\mathrm{CH}_{2} \mathrm{CH}_{2}\right)_{2} \mathrm{Cl}\right]_{2}(5 \%)$, (S)-DTBM-BIPHEP (10\%);

$\mathrm{PCy}_{3}(10 \%), \mathrm{AgBF}_{4}(20 \%)$;

1,4-Dioxane $(0.025 \mathrm{M}) ; 40^{\circ} \mathrm{C}$<smiles>[R]C1=C2CNC[C@H]2C=C2CCC[C@@H]21</smiles>

5<smiles>[R]C=C1CN(C)CC=C1C1=CCCC1</smiles>

\begin{tabular}{|c|c|c|c|c|c|}
\hline Entry $^{a}$ & Substitutents & Yield $(\%)^{b}$ & Ratio $^{c}$ & $D r^{d}$ & ee $(\%)^{\mathrm{e}}$ \\
\hline 1 & $n=1, \mathrm{R}=3-\mathrm{F}-\mathrm{C}_{6} \mathrm{H}_{4}$ & 93 & $5 a: 6 a=78: 22$ & $>20: 1$ & 99 \\
\hline 2 & $n=2, \mathrm{R}=\mathrm{Ph}$ & 98 & $5 b: 6 b=50: 50$ & $>20: 1$ & 90 \\
\hline 3 & $n=2, \mathrm{R}=3-\mathrm{F}-\mathrm{C}_{6} \mathrm{H}_{4}$ & 95 & $5 c: 6 c=93: 7$ & $>20: 1$ & 98 \\
\hline 4 & $n=2, \mathrm{R}=2$-thiophenyl & 92 & $5 d: 6 d=72: 28$ & $>20: 1$ & 97 \\
\hline
\end{tabular}

a The reactions were conducted with 4 (0.1 mmol) with in situ generated complex with (S)-DTBM-BIPHEP $(10 \mathrm{~mol} \%), \mathrm{PCy}_{3}(10 \mathrm{~mol} \%),\left[\left\{\mathrm{Rh}\left(\mathrm{CH}_{2} \mathrm{CH}_{2}\right)_{2} \mathrm{Cl}_{2}\right](5 \mathrm{~mol} \%)\right.$ in the presence of $\mathrm{AgBF}{ }_{4}(20 \mathrm{~mol}$ $\%)$ in 1,4-dioxane at $40^{\circ} \mathrm{C}$ unless otherwise noted

The combined yield of $\mathbf{5}$ and $\mathbf{6}$, isolated yields were reported

c, dDetermined by ${ }^{1} \mathrm{H}-\mathrm{NMR}$ of the mixture

eDetermined by HPLC using a chiral stationary phase, see Supplementary Figures $52-55$

a

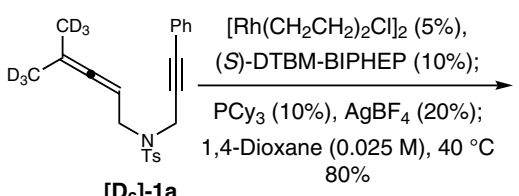

$\left[\mathrm{D}_{6}\right]-1 \mathrm{a}$ $80 \%$

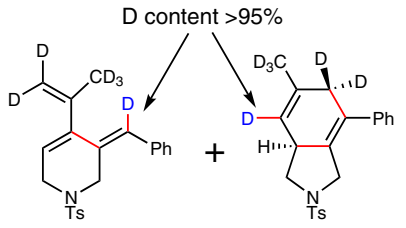

$\left[D_{6}\right]-3 a$

$\left[D_{6}\right]-2 a$

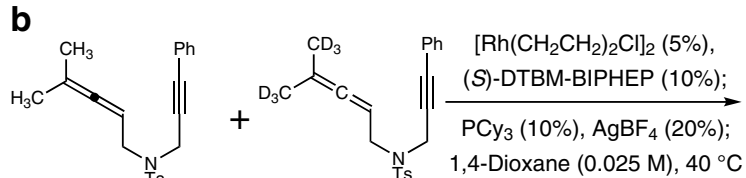

$1 \mathrm{a}$
$\left(D_{6}\right)-1 a$

$1 a:\left[D_{6}\right]-1 a=1:$

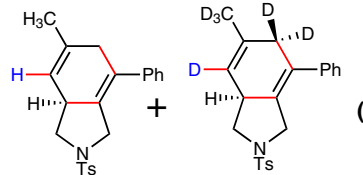

$2 a$

$2 \mathrm{a}+\left[\mathrm{D}_{6}\right]-2 \mathrm{a}=12-20 \%$ yield

$2 a:\left[D_{6}\right]-2 a=68: 32 \sim 73: 27$

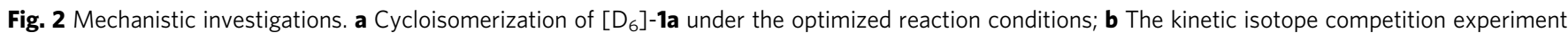
by using the mixture of $\mathbf{1 a}$ and $\left[D_{6}\right]-\mathbf{1 a}$

extensive DFT (M06-L/6-31 G* was used for the geometry optimization) study was conducted on seven possible pathways (i-vii) using the ligand $\mathbf{L 4}$, with $\mathrm{PMe}_{3}$ and substrate 1a (with 249 atoms in total). In addition, for the most possible pathway (i-Ph), $\mathrm{PPh}_{3}$ ligand was employed as opposed to $\mathrm{PMe}_{3}$ in order to draw a better comparison with the actual experimental results.

Although the formation of the 5/6-fused bicycle[4.3.0]nonadienes and Alder-ene type products could be rationalized by the common initial oxidative cyclization pathways to form the rhoda (III)bicyclic intermediates (Fig. 4), these common pathways were not supported by different DFT methods (M06-L, M06, PW6B95D3, B3LYP-D3, B3PW91-D3, BP86-D3, PBE0-D3 and wB97XD methods for the energy calculations) due to their higher barriers (Figs. 3-5). As shown in Figs. 3-5, Supplementary Figures 56-62 and Table 4, our computational results emerged a uncommon pathway that the most favorable pathway starts from a stable rhodium(I) complex APh (Fig. 3 and Fig. 4$)^{40}$, in which the two phosphine atoms of $\mathbf{L 4}$ and $\mathrm{aPh}_{3}$ ligand as well as the alkyne moiety of 1a coordinate to the acidic rhodium(I) metal. Then, the cationic metal complex APh preferentially undergoes 5-exo-dig cyclization with two new $\mathrm{C}-\mathrm{C}$ bond formations to give a stable rhodium(I)-carbenoid complex $\mathbf{B P h}_{\mathbf{R}}(\Delta G=-2.9 \mathrm{kcal} / \mathrm{mol})$ with a barrier of about $22.4 \mathrm{kcal} / \mathrm{mol}$ in solution by the M06-L method. The similar computed barrier was also obtained from different DFT methods ( $22.4-25.8 \mathrm{kcal} / \mathrm{mol}$, Table 4$)$. The 5-exo-dig cyclization is subsequently followed by a ring expansion to form a more stable bicyclic intermediate $\mathbf{C P h}$ (formal $[2+2]$ cycloaddition product) ${ }^{11,12,36,41-44}$. Such transformation is (partly) analogous to Pt/Au-catalyzed cycloisomerization of allenynes ${ }^{23,35,36,41-}$ 44. After dissociation of the bulky $\mathrm{PPh}_{3}$ ligand from $\mathbf{C P h}$ and shift of another rhodium(I)-alkene coordination mode to form $\mathbf{D}^{\prime}$ $(\Delta G=-14.8 \mathrm{kcal} / \mathrm{mol})$, isomerization of this alkene part from the methylethylidene moiety proceed. This $\mathrm{Rh}(\mathrm{I})$-catalyzed isomerization involves oxidative addition through $\mathbf{T S}_{\mathbf{D}-\mathbf{E}}^{\prime}$ to give an unstable $\eta^{3}$-allyl rhodium(III)-hydride intermediate $\mathbf{E}^{\prime}(\Delta G=0.7$ $\mathrm{kcal} / \mathrm{mol}$ ). Such $\mathrm{Rh}(\mathrm{I})$-mediated allylic $\mathrm{C}_{\mathrm{sp} 3}-\mathrm{H}$ activation was also proposed to be involved in another $\mathrm{Rh}(\mathrm{I})$-catalyzed cycloisomerization reactions ${ }^{40,45,46}$. Notably, this $\mathrm{Rh}(\mathrm{I})$-catalyzed $\mathrm{C}_{\mathrm{sp} 3}-\mathrm{H}$ 


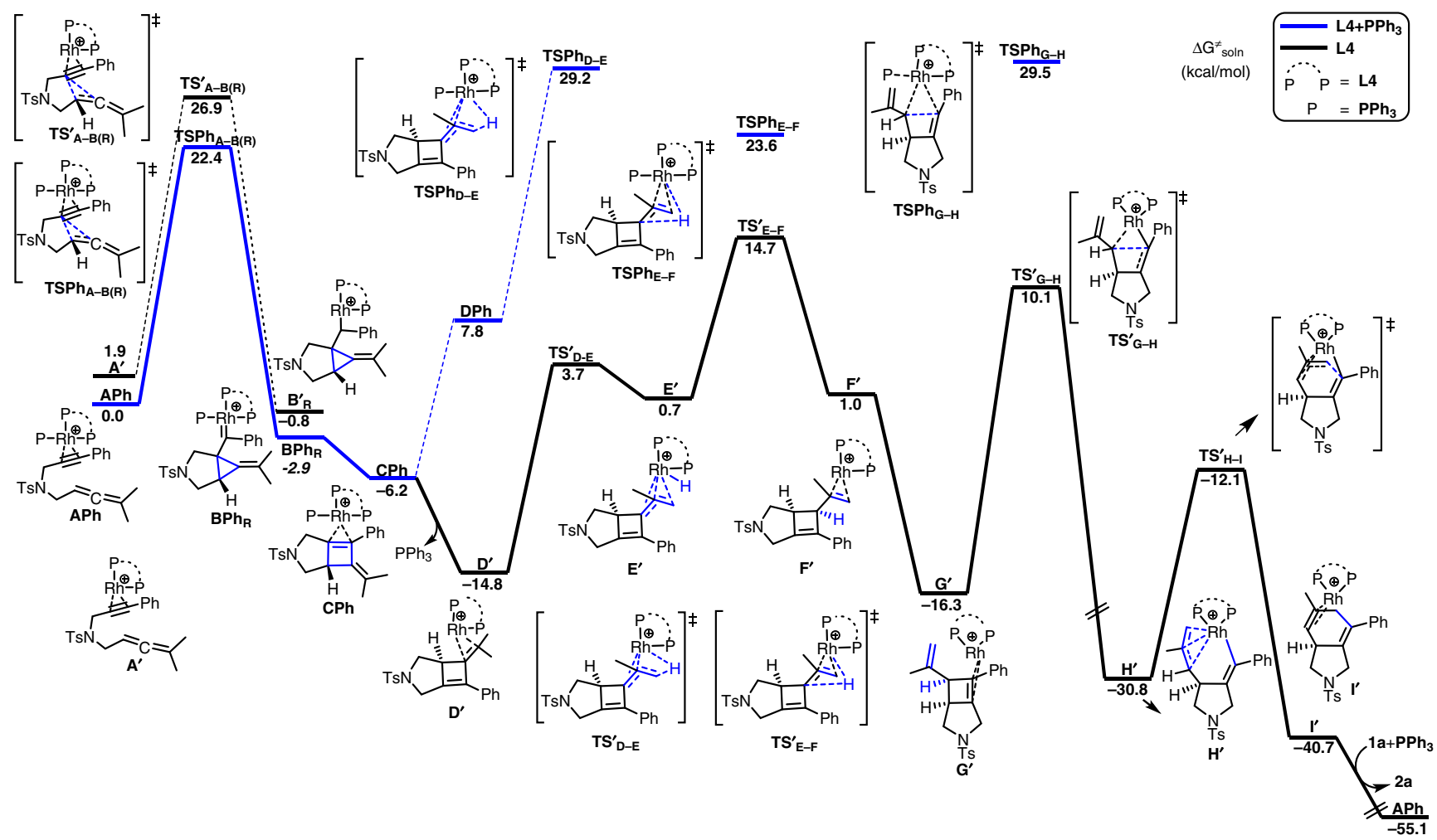

Fig. 3 DFT Results. The computed free energy profiles for the most possible pathway (i-Ph) of the Rh(I)-catalyzed cycloisomerization of 1,6-allenyne (1a) in solution by SMD M06-L//M06-L method

Table 4 The relative free energies (in $\mathrm{kcal} / \mathrm{mol}$ ) of the most possible pathway (i-Ph) and the barrier for the lowest-energy sidereaction oxidative coupling pathway (via $\mathrm{TS}_{\mathrm{P}-\mathrm{Q}}$ ) for the $\mathrm{Rh}(\mathrm{I})$-catalyzed cycloisomerization of a 1,6-allenyne (1a) in solution phase by different DFT methods (except PW6B95-D3 in gas phase). $\mathrm{PPh}_{3}$ was used as the additional ligand

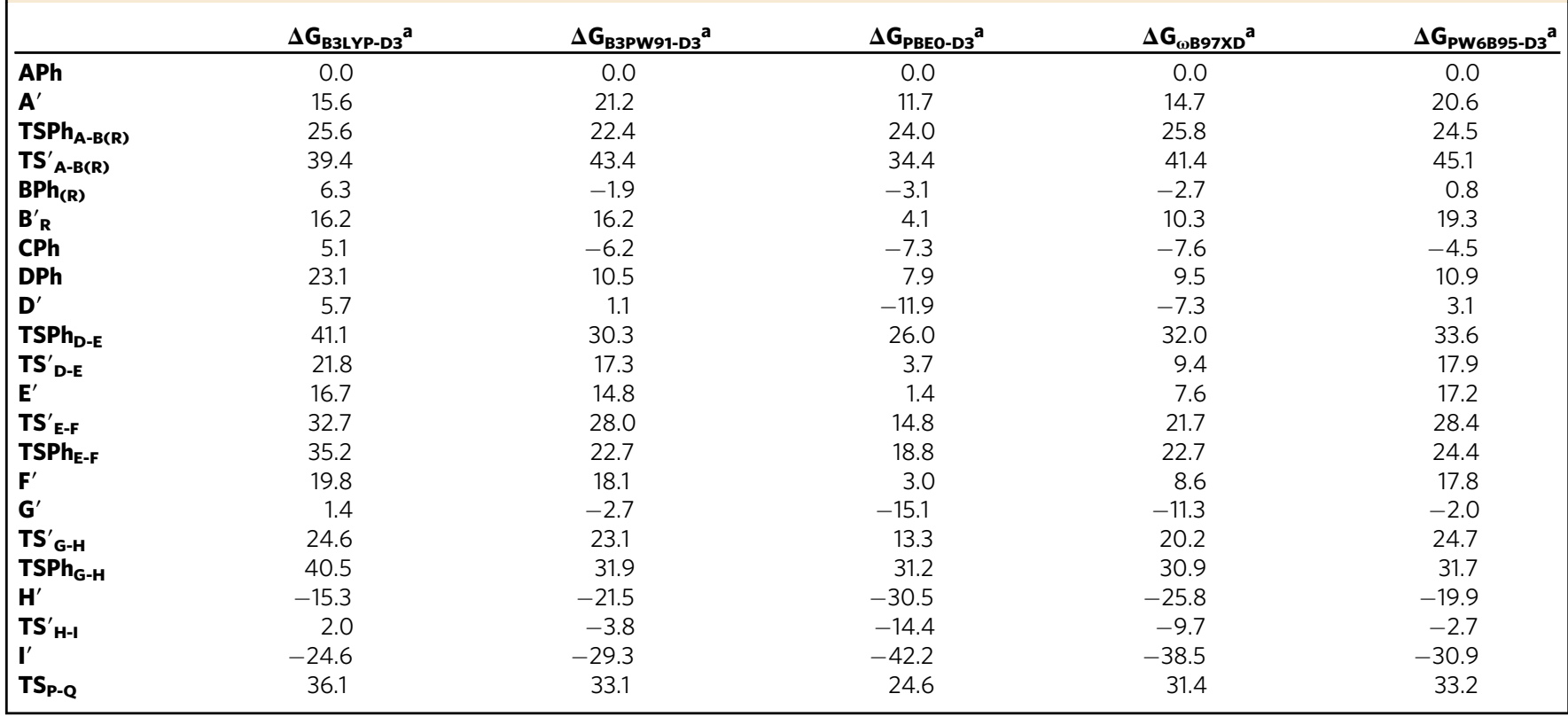

activation (oxidative addition) process is different from the common pathway involving $\beta$-hydride elimination from rhoda (III)bicyclic intermediates (see Fig. 1 and 4). Then, the ratedetermining rhodium(III)-mediated allylic $\mathrm{C}_{\mathrm{sp} 3}-\mathrm{H}$ bond-forming reductive elimination via $\mathbf{T S}_{\text {E-F }}^{\prime}$ takes place to give rhodium(I) intermediates $\mathbf{F}^{\prime}$ and $\mathbf{G}^{\prime}$ with an overall barrier of $\sim 29.5 \mathrm{kcal} / \mathrm{mol}$ above $\mathbf{D}^{\prime}$. Such isomerization transforms intermediate $\mathbf{D}^{\prime}$ with the tetrasubstituted alkene moieties into intermediate $\mathbf{F}^{\prime}$ and $\mathbf{G}^{\prime}$ with the disubstituted alkene moieties. The alkene isomerization step is followed by the rhodium(I)-catalyzed C-C bond 


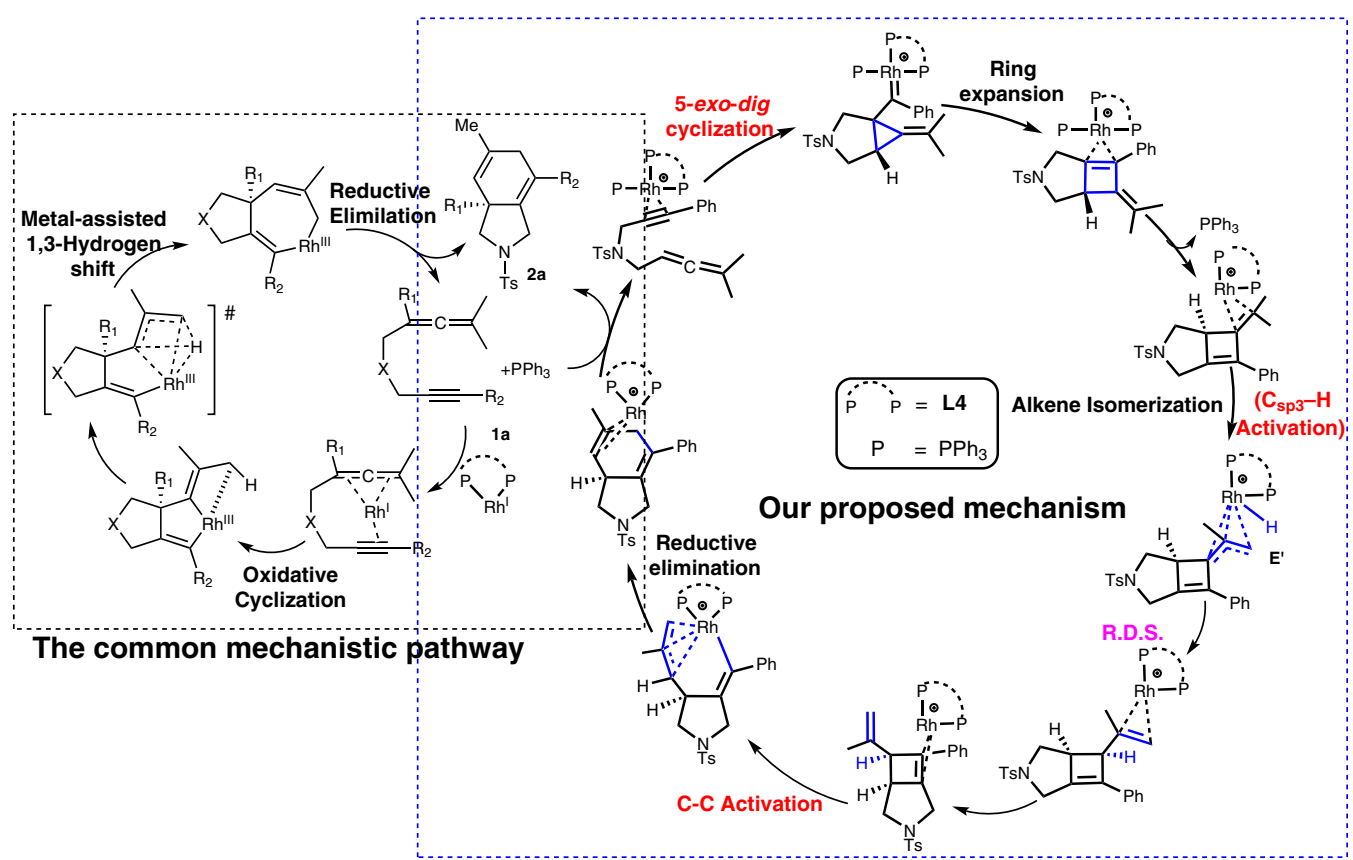

Fig. 4 The mechanistic pathways. The common pathway and our proposed pathway for the uncommon formation of 5/6-Fused Bicycle[4.3.0]nonadienes

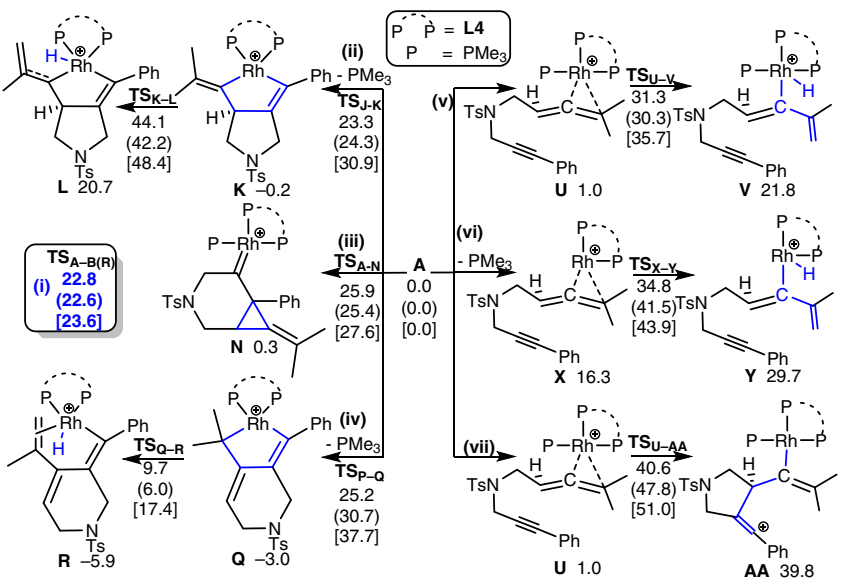

Fig. 5 Computational studies on several pathways. The free energy profiles for different reaction pathways of the cationic $\mathrm{Rh}(\mathrm{I})$-catalyzed cycloisomerization of 1,6-allenyne (1a) using a $\mathrm{PMe}_{3}$ ligand in solution by the SMD M06-L//M06-L method. The relative free energy for the key transition states by SMD PBEO-D3//M06-L and SMD B3LYP-D3//M06-L methods are also given in parenthesis and bracket, respectively

activation ${ }^{21,47-49}$ of the cyclobutene moiety of $\mathbf{G}^{\prime}$ via $\mathbf{T S}^{\prime}{ }_{\mathbf{G}-\mathbf{H}}$ to give a stable rhodacycle intermediate $\mathbf{H}^{\prime}$ by overcoming the barrier of roughly $26.4 \mathrm{kcal} / \mathrm{mol}$ above $\mathrm{G}^{\prime}$. Again, such C-C bond activation process involving rhodium(I)-catalyzed oxidative addition is also different from that in the common pathways involving the rhoda(III)bicyclic intermediates (Fig. 1 and 4). Finally, $\mathrm{C}-\mathrm{C}$ forming reductive elimination completes the reaction to afford the desired 5/6-fused bicyclic product $\mathbf{I}^{\prime}$ with regeneration of a cationic $\mathrm{Rh}(\mathrm{I})$ complex. The overall process was computed to be exergonic by about $55.1 \mathrm{kcal} / \mathrm{mol}$ in solution. In general, different DFT methods give a qualitatively similar mechanistic picture and suggest the highest overall barrier for the $\mathrm{C}_{\mathrm{sp3}}-\mathrm{H}$ bond-forming reductive elimination, which is in qualitatively agreement with our KIE experiments (Fig. 2$)^{50}$. This mechanism involving the uncommon 5-exo-dig cyclization, rhodium(I)-catalyzed $\mathrm{C}-\mathrm{H}$ bond activation and $\mathrm{C}-\mathrm{C}$ bond activation steps was proposed to be the key factor to form the unusual 5/6-fused bicycle[4.3.0]nonadienes.

In comparison, different DFT methods also show that the lowest-energy side-reaction oxidative coupling pathway (via $\mathbf{T S}_{\mathbf{P}}$ Q) generally has a larger barrier than that for the abovementioned 5-exo-dig cyclization via $\mathbf{T S P h}_{\mathbf{A}-\mathbf{B}(\mathbf{R})}$. These computational results demonstrated that the second $\mathrm{PPh}_{3}$ ligand play a critical role in directing the reaction towards the initial 5-exo-dig cyclization step and suppressing the common initial oxidative coupling pathway. In the absence of the $\mathrm{PPh}_{3}$ ligand, 1,4-dioxane molecule might coordinate to the rhodium(I) metal center and thus disfavor the oxidative coupling pathway to form the Alderene type product.

The overall reaction mechanism for the most favorable pathway is slightly different, when a smaller $\mathrm{PMe}_{3}$ ligand was used to replace $\mathrm{PPh}_{3}$ as the monodentate ligand. Notably, the computed barrier for the 5-exo-dig cyclization with the $\mathrm{PMe}_{3}$ ligand is quite similar $(22.8 \mathrm{kcal} / \mathrm{mol})$; however, the bulky $\mathrm{PPh}_{3}$ ligand is only involved in the first stage of the cycloisomerization and then dissociates from the metal, presumably due to steric repulsion with the bulky $\mathbf{L} 4$ ligand and substrate. In contrast, $\mathrm{PMe}_{3}$ can recoordinate to the metal center in the key $\mathrm{C}_{\mathrm{sp} 3}-\mathrm{H}$ bond-forming reductive elimination step. In comparison, our DFT results show that the common pathways (such as initial 6-endo-dig cyclization (pathway iii), initial oxidative coupling between the alkyne and allene parts (pathways ii and iv), initial $\mathrm{C}_{\mathrm{sp} 3}-\mathrm{H}$ activation (pathways $\mathbf{v}$ and $\mathbf{v i}$ ) and initial single $\mathrm{C}-\mathrm{C}$ bond forming (pathway vii), see Fig. 5) were computed to have higher barriers than the 5exo-dig cyclization via $\mathbf{T S}_{\mathbf{A}-\mathbf{B}(\mathbf{R})}$ in the most favorable pathway (i), presumably due to a stronger binding affinity of $\mathrm{PMe}_{3}$ than the alkene and a more bulky ligand L4 disfavoring the abovementioned common pathways. Our proposed most favorable pathway was also supported by different DFT methods (Supplementary Tables 2-27). Moreover, our DFT calculations also suggest that the alkene isomerization step with the new $\mathrm{C}-\mathrm{H}$ bond formation is the possible rate-determining step. 


\section{Discussion}

In summary, this study developed an enantioselective ligandcontrolled rhodium(I)-catalyzed cycloisomerization of 1,6-allenynes for the synthesis of 5/6-fused bicycle[4.3.0]nonadiene skeletons through a 5-exo-dig cyclization pathway. Notably, this synthetic method also works for cyclic 1,6-allenynes to afford the diastereoselective construction of tricyclic products, which are challenging for classical synthetic methods and will be important for applications in drug and natural products synthesis. Although both 5-exodig and 6-endo-dig pathways are not surprising in metal-catalyzed alkyne closure ${ }^{51-53}$ and it is quite common for those with gold catalysts to provide 5-exo-dig products ${ }^{51,54-58}$, it is very unusual for rhodium catalysts to favor a 5-exo-dig pathway ${ }^{58}$, thereby preferentially forming the proximal product (via $5 / 5$ rhodacyclic intermediate) rather than the distal product (via $6 / 5$ rhodacyclic intermediate $)^{59}$. Our systematic DFT study provides an insight over the classical mechanistic pathways (such as initial 6-endo-dig cyclization, initial oxidative coupling between the alkyne and allene parts and $\mathrm{C}_{\mathrm{sp} 3}-\mathrm{H}$ activation). Hence, the calculations suggest a uncommon pathway initiated with a rare 5-exo-dig cyclization followed by ring expansion, alkene isomerization via ratedetermining rhodium(I)-catalyzed $\mathrm{C}-\mathrm{H}$ bond activation, rhodium (I)-catalyzed $\mathrm{C}-\mathrm{C}$ bond activation of the cyclobutene moiety and final $\mathrm{C}-\mathrm{C}$ bond-forming reductive elimination was the most favorable pathway. Deuterium labeling experiments further support the rate-determining step involving the $\mathrm{C}-\mathrm{H}$ bond activation in this transformation. The present chemical transformation provides a highly regio- and stereoselective transformation, which was attained by the screening of ligands, solvents and additives. Further studies on the application of this method to the synthesis of natural products are in progress.

\section{Methods}

Procedures for synthesis of $\mathbf{2}$ and $\mathbf{5}$. In an oven-dried Shlenk tube, [Rh $\left.\left(\mathrm{CH}_{2} \mathrm{CH}_{2}\right)_{2} \mathrm{Cl}\right]_{2}(0.005 \mathrm{mmol})$ and the chiral diphosphane ligand $(0.01 \mathrm{mmol})$ were dissolved in freshly distilled 1,4-dioxane $(1.0 \mathrm{~mL})$. The mixture was stirred at $25^{\circ} \mathrm{C}$ under argon for $0.5 \mathrm{~h}$. Then $\mathrm{PCy}_{3}(0.01 \mathrm{mmol})$ was added to the solution and was stirred at $25^{\circ} \mathrm{C}$ for additional $6 \mathrm{~h}$. Then $\mathrm{Ag}(\mathrm{I})$ salt $(0.02 \mathrm{mmol})$ was added to the mixture and was stirred for further $15 \mathrm{~min}$, followed by adding 1,4-dioxane $(3 \mathrm{~mL})$ and the 1,6-allenyne 1 or $4(0.1 \mathrm{mmol})$ successively. The resulting mixture was stirred at $40^{\circ} \mathrm{C}$ under argon until no starting material was detected by TLC. Upon the completion of the reaction, the solvent was removed. The crude mixture was directly subjected to column Chromatography on silica gel using petrol ether/ EtOAc (30:1-10:1) as eluent to give the desired product.

Procedures for synthesis of $\mathbf{3}$ and 6. In a oven-dried Shlenk tube, [Rh $\left.\left(\mathrm{CH}_{2} \mathrm{CH}_{2}\right)_{2} \mathrm{Cl}\right]_{2}(0.0025 \mathrm{mmol})$ and $( \pm)$-BINAP $(0.005 \mathrm{mmol})$ were dissolved in freshly distilled 1,4 -dioxane $(1.0 \mathrm{~mL})$. The mixture was stirred at $25^{\circ} \mathrm{C}$ under argon for $0.5 \mathrm{~h}$. Then $\mathrm{Ag}^{\mathrm{I}}$ salt $(0.01 \mathrm{mmol})$ was added to the mixture and was stirred for further $15 \mathrm{~min}$, followed by adding 1,4-dioxane $(1 \mathrm{~mL})$ and the 1,6-allenyne 1 or 4 $(0.1 \mathrm{mmol})$ successively. The resulting mixture was stirred at $25^{\circ} \mathrm{C}$ under argon until no starting material was detected by TLC. Upon the completion of the reaction, the solvent was removed. The crude mixture was directly subjected to column Chromatography on silica gel using petrol ether/EtOAc $(30: 1-10: 1)$ as eluent to give the desired product.

Measurement of enantiomeric excess (ee). Racemic $5 / 6$ bicylic products were prepared with $( \pm)$-DTBM-BIPHEP as the chiral ligand according to the general procedure described above. Similarly, optically active 5/6 bicyclic products were prepared with $(S)$-DTBM-BIPHEP as the chiral ligand according to the procedure described above. The ee value was determined by chiral HPLC (CHIRALPAK AD$\mathrm{H}, \mathrm{OD}-\mathrm{H}, \mathrm{AS}-\mathrm{H}$ and IB-H column).

Computational Details. All DFT calculations were performed using the Gaussian 09 program $^{60,61}$, except for the single-point gas-phase calculations by PW6B95D3 method, which were performed by the Gaussian 16 program. M06-L method was used to fully optimize the reactants, intermediates, products and transition states (TS) in gas phase. The $6-31 \mathrm{G}^{*}$ basis set was used for $\mathrm{H}, \mathrm{C}, \mathrm{N}, \mathrm{O}, \mathrm{P}, \mathrm{S}$ and $\mathrm{Cl}$ atoms, while the SDD basis set and its effective-core potential were used for the Rh and Ag atom. Frequency calculations were then carried out to confirm transition states with one imaginary frequency and minima without imaginary frequency. Solvent effects (1,4-dioxane) were also included through implicit SMD solvent model ${ }^{60}$ by carrying single-point solvent calculations on the optimized geometries in gas phase Single-point calculations in solution by several functionals (B3LYP-D3, B3PW91D3, BP86-D3, M06, PBE0-D3 and $\omega B$ 97XD) $)^{62-64}$ were also performed to examine effect of the functionals on the energetic profiles. Moreover, single-point calculations in gas phase PW6B95D3 were also carried out.

\section{Data availability}

Crystallographic data for the structure $\mathbf{2} \mathbf{g}$ reported in this paper have been deposited at the Cambridge Crystallographic Data Centre under deposition number CCDC 1586680. Copies of the data can be obtained free of charge via www.ccdc.cam.ac.uk. All other data supporting the findings of this study, including experimental procedures and compound characterization, are available within the paper and its Supplementary Information, or from the corresponding author upon reasonable request.

Received: 30 November 2018 Accepted: 11 January 2019 Published online: 27 February 2019

\section{References}

1. Trost, B. M. The atom economy: a search for synthetic efficiency. Science 254, 1471-1477 (1991).

2. Aubert, C., Fensterbank, L., Garcia, P., Malacria, M. \& Simonneau, A. Transition metal catalyzed cycloisomerizations of 1,n-allenynes and -allenenes. Chem. Rev. 111, 1954-1993 (2011).

3. Llerena, D., Aubert, C. \& Malacria, M. First examples of cobalt-mediated formal Alder ene reaction of allenynes. Tetrahedron Lett. 37, 7027-7030 (1996).

4. Brummond, K. M., Chen, H., Sill, P. \& You, L. A Rhodium(I)-catalyzed formal allenic Alder Ene reaction for the rapid and stereoselective assembly of crossconjugated trienes. J. Am. Chem. Soc. 124, 15186-15187 (2002).

5. Shibata, T., Takesue, Y., Kadowaki, S. \& Takagi, K. Rhodium complex-catalyzed intramolecular ene-type reaction of allenynes. Synlett 2003, 268-270 (2003).

6. Brummond, K. M., Painter, T. O., Probst, D. A. \& Mitasev, B. Rhodium(I)catalyzed allenic carbocyclization reaction affording $\delta$ - and $\varepsilon$-lactams. Org. Lett. 9, 347-349 (2007)

7. Brummond, K. M. \& Mitasev, B. Allenes and transition metals: a diverging approach to heterocycles. Org. Lett. 6, 2245-2248 (2004).

8. Park, J. H., Kim, S. Y., Kim, S. M., Lee, S. I. \& Chung, Y. K. Allenic PausonKhand reaction catalyzed by cobalt-rhodium heterobimetallic nanoparticles. Synlett 2007, 453-459 (2007).

9. Jiang, X. \& Ma, S. trans- $\mathrm{RhCl}(\mathrm{CO})\left(\mathrm{PPh}_{3}\right)_{2}$-catalyzed monomeric and dimeric cycloisomerization of propargylic 2,3-dienoates. establishment of $\alpha, \beta$ unsaturated $\delta$-lactone rings by cyclometallation. J. Am. Chem. Soc. 129, 11600-11607 (2007).

10. Quan, S., Wang, Y., Zheng, K. \& Tong, X. Rh(III)-catalyzed hydrative cyclization of 1,6-allenynes: synthesis of six-membered nitrogen and oxygen heterocycles. Tetrahedron Lett. 56, 215-217 (2015).

11. Oonishi, Y., Kitano, Y. \& Sato, Y. C. (sp3)-H bond activation triggered by formation of metallacycles: rhodium(I)-catalyzed cyclopropanation/ cyclization of allenynes. Angew. Chem., Int. Ed. 51, 7305-7308 (2012).

12. Mukai, C., Ohta, Y., Oura, Y., Kawaguchi, Y. \& Inagaki, F. Csp3 -Csp3 and Csp3 $-\mathrm{H}$ bond activation of 1,1-disubstituted cyclopentane. J. Am. Chem. Soc. 134, 19580-19583 (2012)

13. Kawaguchi, Y., Yasuda, S., Kaneko, A., Oura, Y. \& Mukai, C. Rhodium(I)catalyzed cycloisomerization of benzylallene-alkynes through $\mathrm{C}-\mathrm{H}$ activation. Angew. Chem., Int. Ed. 53, 7608-7612 (2014).

14. Kawaguchi, Y., Yasuda, S. \& Mukai, C. Construction of hexahydrophenanthrenes by rhodium(I)-catalyzed cycloisomerization of benzylallene-substituted internal alkynes through $\mathrm{C}-\mathrm{H}$ activation. Angew. Chem., Int. Ed. 55, 10473-10477 (2016).

15. Kawaguchi, Y., Yasuda, S. \& Mukai, C. Mechanistic investigation of Rh(I)catalyzed cycloisomerization of benzylallene-internal alkynes via $\mathrm{C}-\mathrm{H}$ activation. J. Org. Chem. 82, 7666-7674 (2017).

16. Inagaki, F., Sugikubo, K., Oura, Y. \& Mukai, C. Rh(I)-Catalyzed [6+2] cycloaddition of alkyne-allenylcyclobutanes: a new entry for the synthesis of bicyclo[6.m.0] skeletons. Chem. Eur. J. 17, 9062-9065 (2011).

17. Kawamura, T., Kawaguchi, Y., Sugikubo, K., Inagaki, F. \& Mukai, C. Rhodium (I)-catalyzed cycloisomerization of allene-allenylcyclopropanes. Eur. J. Org. Chem. 2015, 719-722 (2015).

18. Yasuda, S., Yokosawa, H. \& Mukai, C. Construction of azabicyclo[6.4.0] dodecatrienes based on rhodium(I)-catalyzed intramolecular [6+2] cycloaddition between azetidine, allene, and alkynes. Chem. Pharm. Bull. 64, 805-810 (2016).

19. Mukai, C. \& Yasuda, S. Rh(I)-catalyzed cycloaddition between allenyl $\pi$-bonds and C-C triple bonds. Yuki Gosei Kagaku Kyokaishi 74, 1108-1118 (2016). 
20. Huang, G. Mechanism and selectivity in rhodium-catalyzed [7+2] cycloaddition and cyclopropanation/cyclization of allenylcyclopentanealkynes: metallacycle-directed C(sp3)-C(sp3) vs C(sp3)-H Activation. J. Org. Chem. 80, 7564-7571 (2015).

21. Murakami, M. \& Matsuda, T. Metal-catalysed cleavage of carbon-carbon bonds. Chem. Comm. 47, 1100-1105 (2011).

22. Aïssa, C. Transition-metal-catalyzed rearrangements of small cycloalkanes: regioselectivity trends in $\beta$-carbon elimination reactions. Synthesis $\mathbf{4 3}$, 3389-3407 (2011).

23. Huang, G. Mechanism of rhodium-catalyzed cyclopropanation/cyclization of allenynes. Org. Lett. 17, 1994-1997 (2015).

24. Inagaki, F., Sugikubo, K., Miyashita, Y. \& Mukai, C. Rhodium(I)-catalyzed intramolecular [5+2] cycloaddition reactions of alkynes and allenylcyclopropanes: construction of Bicyclo[5.4.0]undecatrienes and Bicyclo [5.5.0]dodecatrienes. Angew. Chem. Int. Ed. 49, 2206-2210 (2010).

25. Yamaguchi, J., Yamaguchi, A. D. \& Itami, K. C-H bond functionalization: emerging synthetic tools for natural products and pharmaceuticals. Angew. Chem., Int. Ed. 51, 8960-9009 (2012).

26. Cao, P., Wang, B. \& Zhang, X. Rh-catalyzed enyne cycloisomerization. J. Am. Chem. Soc. 122, 6490-6491 (2000).

27. Cao, P. \& Zhang, X. The First highly enantioselective Rh-catalyzed enyne cycloisomerization. Angew. Chem., Int. Ed. 39, 4104-4106 (2000).

28. Lei, A., He, M., Wu, S. \& Zhang, X. Highly enantioselective Rh-catalyzed intramolecular Alder-ene reactions for the syntheses of chiral tetrahydrofurans. Angew. Chem., Int. Ed. 41, 3457-3460 (2002)

29. Lei, A., He, M. \& Zhang, X. Highly enantioselective syntheses of functionalized $\alpha$-methylene- $\gamma$-butyrolactones via $\mathrm{Rh}(\mathrm{I})$-catalyzed intramolecular alder ene reaction: application to formal synthesis of (+)-Pilocarpine. J. Am. Chem. Soc. 124, 8198-8199 (2002).

30. Lei, A., He, M. \& Zhang, X. Rh-catalyzed kinetic resolution of enynes and highly enantioselective formation of 4-alkenyl-2,3-disubstituted tetrahydrofurans. J. Am. Chem. Soc. 125, 11472-11473 (2003).

31. Deng, X. et al. Enantioselective rhodium-catalyzed cycloisomerization of $(E)$ 1,6-enynes. Angew. Chem., Int. Ed. 55, 6295-6299 (2016).

32. Miura, T., Ueda, K., Takahashi, Y. \& Murakami, M. Rhodium-catalysed cyclisation reaction of allenynes with arylboronic acids. Chem. Comm., 5366-5368 (2008).

33. Oonishi, Y., Hosotani, A. \& Sato, Y. Construction of monocyclic eightmembered rings: intermolecular rhodium(I)-catalyzed [6+2] cycloaddition of 4-allenals with alkynes. Angew. Chem., Int. Ed. 51, 11548-11551 (2012).

34. Ohta, Y., Yasuda, S., Yokogawa, Y. \& Kurokawa, K. Mukai c. stereospecific and stereoselective rhodium(l)-catalyzed intramolecular $[2+2+2]$ Cycloaddition of Allene-Ene-Ynes: Construction of Bicyclo[4.1.0]heptenes. Angew. Chem. Int. Ed. 54, 1240-1244 (2015).

35. Jaroschik, F. et al. Assessing ligand and counterion effects in the noble metal catalyzed cycloisomerization reactions of 1,6-allenynes: a combined experimental and theoretical approach. ACS Catal. 6, 5146-5160 (2016).

36. Nishimura, T., Kawamoto, T., Nagaosa, M., Kumamoto, H. \& Hayashi, T. Chiral tetrafluorobenzobarrelene ligands for the rhodium-catalyzed asymmetric cycloisomerization of oxygen- and nitrogen-bridged 1,6-enynes. Angew. Chem., Int. Ed. 49, 1638-1641 (2010).

37. Nishimura, T., Maeda, Y. \& Hayashi, T. Chiral diene-phosphine tridentate ligands for rhodium-catalyzed asymmetric cycloisomerization of 1,6-enynes. Org. Lett. 13, 3674-3677 (2011).

38. Nishimura, T., Takiguchi, Y., Maeda, Y. \& Hayashi, T. Rhodium-catalyzed asymmetric cycloisomerization of 1,6-ene-ynamides. Adv. Synth. Catal. 355, 1374-1382 (2013).

39. Saito, N., Tanaka, Y. \& Sato, Y. Ruthenium-catalyzed [2+2] cycloaddition of allenynes leading to a bicyclo[4.2.0]octa-1(8),5-diene skeleton. Org. Lett. 11, 4124-4126 (2009).

40. Vidhani, D. V., Krafft, M. E. \& Alabugin, I. V. Rh(I)-catalyzed transformation of propargyl vinyl ethers into $(E, Z)$-dienals: stereoelectronic role of trans effect in a metal-mediated pericyclic process and a shift from homogeneous to heterogeneous catalysis during a one-pot reaction. J. Org. Chem. 79, 352-364 (2014).

41. Soriano, E. \& Marco-Contelles, J. Mechanistic insights on the cycloisomerization of polyunsaturated precursors catalyzed by platinum and gold complexes. Acc. Chem. Res. 42, 1026-1036 (2009).

42. de Orbe, M. E. et al. Cyclobutene vs 1,3-diene formation in the gold-catalyzed reaction of alkynes with alkenes: the complete mechanistic picture. J. Am. Chem. Soc. 139, 10302-10311 (2017).

43. Dorel, R. \& Echavarren, A. M. Gold(I)-catalyzed activation of alkynes for the construction of molecular complexity. Chem. Rev. 115, 9028-9072 (2015).

44. Zhuo, L.-G., Zhang, J.-J. \& Yu, Z.-X. DFT and experimental exploration of the mechanism of $\operatorname{lnCl}_{3}$-catalyzed type 11 cycloisomerization of 1,6-enynes: identifying $\mathrm{InCl}_{2}{ }^{+}$as the catalytic species and answering why nonconjugated dienes are generated. J. Org. Chem. 77, 8527-8540 (2012).
45. Li, Q. \& Yu, Z.-X. Conjugated diene-assisted allylic $\mathrm{C}-\mathrm{H}$ bond activation: cationic $\mathrm{Rh}(\mathrm{l})$-catalyzed syntheses of polysubstituted tetrahydropyrroles, tetrahydrofurans, and cyclopentanes from ene-2-dienes. J. Am. Chem. Soc. 132, 4542-4543 (2010).

46. Li, Q. \& Yu, Z.-X. Density functional theory study of the mechanism of the rhodium(I)-catalyzed conjugated diene assisted allylic $\mathrm{C}-\mathrm{H}$ bond activation and addition to alkenes using ene-2-dienes as substrates. Organometallics $\mathbf{3 1}$, 5185-5195 (2012).

47. Chen, F., Wang, T. \& Jiao, N. Recent advances in transition-metal-catalyzed functionalization of unstrained carbon-carbon bonds. Chem. Rev. 114, 8613-8661 (2014)

48. Souillart, L. \& Cramer, N. Catalytic C-C bond activations via oxidative addition to transition metals. Chem. Rev. 115, 9410-9464 (2015).

49. Chen, P.-H, Billett, B. A., Tsukamoto, T. \& Dong, G. "Cut and sew" transformations via transition-metal-catalyzed carbon-carbon bond activation. ACS Catal. 7, 1340-1360 (2017).

50. Gómez-Gallego, M. \& Sierra, M. A. Kinetic isotope effects in the study of organometallic reaction mechanisms. Chem. Rev. 111, 4857-4963 (2011).

51. Alabugin, I. V. \& Gilmore, K. Finding the right path: Baldwin "Rules for Ring Closure" and stereoelectronic control of cyclizations. Chem. Comm. 49, 11246-11250 (2013).

52. Peterson, P. W., Mohamed, R. K. \& Alabugin, I. V. How to Lose a Bond in Two Ways — The Diradical/Zwitterion Dichotomy in Cycloaromatization Reactions. Eur. J. Org. Chem. 2013, 2505-2527 (2013).

53. Gilmore, K. \& Mohamed, R. K. Alabugin IV. The baldwin rules: revised and extended. Wiley Interdiscip. Rev.: Comput. Mol. Sci. 6, 487-514 (2016).

54. Genin, E. et al. Room temperature Au(I)-catalyzed exo-selective cycloisomerization of acetylenic acids: an entry to functionalized $\gamma$-lactones. $J$ Am. Chem. Soc. 128, 3112-3113 (2006).

55. Hashmi, A. S. K. et al. Selectivity switch in the synthesis of vinylgold(l) intermediates. Organometallics 30, 6328-6337 (2011).

56. Alabugin, I. V., Gilmore, K. \& Manoharan, M. Rules for anionic and radical ring closure of alkynes. J. Am. Chem. Soc. 133, 12608-12623 (2011).

57. Ung, G., Soleilhavoup, M. \& Bertrand, G. Gold(III)- versus gold(I)induced cyclization: synthesis of six-membered mesoionic carbene and acyclic (aryl)(heteroaryl) carbene complexes. Angew. Chem., Int. Ed. 52, 758-761 (2013).

58. Vummaleti, S. V. C., Falivene, L., Poater, A. \& Cavallo, L. Deconstructing selectivity in the gold-promoted cyclization of alkynyl benzothioamides to sixmembered mesoionic carbene or acyclic carbene complexes. ACS Catal. 4, 1287-1291 (2014).

59. Kitagaki, S., Inagaki, F. \& Mukai, C. $[2+2+1]$ Cyclization of allenes. Chem. Soc. Rev. 43, 2956-2978 (2014).

60. Frisch, M. J. et al. Gaussian 09, Revision D.01. (Gaussian, Inc., Wallingford, CT, 2009).

61. Marenich, A. V., Cramer, C. J. \& Truhlar, D. G. Universal solvation model based on solute electron density and on a continuum model of the solvent defined by the bulk dielectric constant and atomic surface tensions. J. Phys. Chem. B 113, 6378-6396 (2009).

62. Zhao, Y. \& Truhlar, D. G. Density functionals with broad applicability in chemistry. Acc. Chem. Res. 41, 157-167 (2008).

63. Minenkov, Y., Occhipinti, G. \& Jensen, V. R. Metal-phosphine bond strengths of the transition metals: a challenge for DFT. J. Phys. Chem. A 113 11833-11844 (2009).

64. Averkiev, B. B. \& Truhlar, D. G. Free energy of reaction by density functional theory: oxidative addition of ammonia by an iridium complex with PCP pincer ligands. Catal. Sci. Technol. 1, 1526-1529 (2011).

\section{Acknowledgements}

We are grateful for the financial support by a grant from the National Natural Science Foundation of China (Grant Nos. 21871212, 21302193, 21372179, 81573314, 21432007, 21402145, 21672096), Start-up funds of Southern University of Science and Technology (X. M. Zhang and L. W. Chung) and Central South University (X. Deng), Nature Science Foundation of Hunan Province (2018JJ3707), the Natural Science Foundation of Hubei Province (2018CFB430), the Shenzhen Nobel Prize Scientists Laboratory Project (C17783101), and Changsha Science and Technology Projects (kq1701088).

\section{Author contribution}

X.D., L-Y.S., J.L. contributed equally to this work. H.L. and X.Z. directed the project. X. D., L-Y.S., H.L. and X.Z. contributed to the conception and design of the experiments. X. D., L-Y.S. and Y-Q.G. performed the experiments and analyzed the data. J.L. and X.Z. carried out the computations. X.D., L-Y.S. and J.L. wrote the manuscript with feedback and guidance from L. W.C., H.L. and X.Z. All authors discussed the experimental results and commented on the manuscript. 


\section{Additional information}

Supplementary Information accompanies this paper at https://doi.org/10.1038/s41467019-08900-z.

Competing interests: The authors declare no competing interests.

Reprints and permission information is available online at http://npg.nature.com/ reprintsandpermissions/

Journal peer review information: Nature Communications thanks Albert Poater and the other anonymous reviewer for their contribution to the peer review of this work.

Publisher's note: Springer Nature remains neutral with regard to jurisdictional claims in published maps and institutional affiliations. (c) Open Access This article is licensed under a Creative Commons Attribution 4.0 International License, which permits use, sharing, adaptation, distribution and reproduction in any medium or format, as long as you give appropriate credit to the original author(s) and the source, provide a link to the Creative Commons license, and indicate if changes were made. The images or other third party material in this article are included in the article's Creative Commons license, unles indicated otherwise in a credit line to the material. If material is not included in the article's Creative Commons license and your intended use is not permitted by statutory regulation or exceeds the permitted use, you will need to obtain permission directly from the copyright holder. To view a copy of this license, visit http://creativecommons.org/ licenses/by/4.0/.

(C) The Author(s) 2019 